\title{
Some Studies on Structural Analysis of Launching Mechanism of Mobile Bridging System
}

\author{
H. R. Mahamulkar ${ }^{1}$, K. A. Mahajan ${ }^{1}$, S Karthikeyan ${ }^{2}$, D. Chavan ${ }^{2}$ \\ ${ }^{1}$ (Department of Mechanical Engineering, M.E.S College of Engineering, S. P. Pune University, India) \\ ${ }^{2}$ (Larsen and Toubro Ltd, HED, Pune)
}

\begin{abstract}
Mobile bridging system is the system which is used for immediate crossing of vehicles across dry and wet gaps. It is heavy duty, easily deployable multi span system which is used in critical operations. Bridge launching mechanism is the integral part of the system mounted on vehicle chassis. Magnitude of forces acting on individual parts is unpredictable during operation since launching mechanism is in dynamic condition. Dynamic force analysis is done by analyzing various forces acted on different assemblies in various conditions. Boom assembly is one of the main parts in this mechanism which takes maximum load of 6.5 tons. It is operated by boom hydraulic cylinder and this cylinder requires approx. $196.05 \mathrm{KN}$ force to make bridge vertical and scissor out total bridge structure. In existing condition the angle between boom and boom cylinder is about $52^{\circ}$ .This paper focuses on reduction of boom cylinder force by changing angle between boom cylinder and boom from $52^{\circ}$ to $56^{\circ}$. The analytical results shows that approx. $25 \%$ reduction in cylinder force has been achieved. The results are validated through Finite Element Analysis.
\end{abstract}

Keywords: Boom assembly, mechanism Dynamic forces, Launching, Mobile Bridge, Finite element analysis

\section{INTRODUCTION}

Bridge is a structure spanning and providing a passage over a gap or barrier [1]. Mobile bridging system is heavy duty, rapidly deployable, foldable system and bridges in this system are temporary known as mobile bridges. These bridges are portable, usually needed to span natural gap which are either wet gaps such as river, or dry gaps such as valley, or artificial gaps such as road, or new gaps due to natural disasters. These bridges allow the vehicles to pass across the gaps. Civil bridges are first targeted to disturb communication and supply routes at the time of some critical situations [2]. Mobile bridging system is 75 to $100 \mathrm{~m}$ long multi-span system having five Scissor Bridges which are made of aluminum alloy and length of each bridge module is 15 to $20 \mathrm{~m}$ and mounted on separate vehicle chassis [3]. This system consists of three major sections; the launching mechanism for lifting and spreading the bridge structure across gap, the piers for bridge resting purpose and the bridge structure. The launching mechanism is an integral part of the system and mounted on vehicle chassis. The bridge structure unfolds and launches its girder which is supported by pier system, providing a readymade bridge across the gap within few minutes. Once the structure has been put in the place, the launching vehicle detaches from the bridge and moves aside to allow the traffic to pass over bridge. Once all the armed vehicles and equipments have crossed, launching vehicle crosses the bridge itself and reattached to the same bridge on the other side for de-launch. The bridge is launched or De-launched from either end. The height of the bridge can be adjusted with the help of telescopic pier system so that it is not easily visible from far [2]. Dnyaneshwar J. Sushir et al. [4] published a paper on failure analysis of centre pin joint used in heavy assault bridge. This paper reports the failure analysis of the centre pin joint used in heavy assault bridge by modifying the design and increasing its load carrying capacity. Bhavesh kumar P. Patel [5] worked on evaluation of bucket capacity, digging force calculations and static force analysis of mini hydraulic backhoe excavator. Prasad Shivdas et al. [6] worked on advantage of six bar mechanism as against the existing four bar mechanism used in articulation of the missile launcher system. Werner Fraundorfer [7] developed an attachment for transporting and launching military bridges with light armored vehicles.

\section{PROBLEM FORMULATION}

In recent years, mobile bridges are used in various situations including critical, strategic and general communication purpose. Thus, it is essential to provide launching equipments of maximum reliability as well as having minimum stiffness and weight, by keeping design safe under all loading conditions. Mobile bridges are heavy structures which needs lifting and placing mechanism i.e. bridge launching mechanism. Bridge launching mechanism is the prime important part of the system which is mounted on vehicle chassis and it launches the bridge structure across the gap. This mechanism includes four main sub assemblies which are cradle arm, lifting boom, resting pad and bridge connecting assembly. Lifting boom assembly is used for lifting and pushing heavy 
structure with the help of hydraulic cylinder pressure. This paper focuses on reduction in boom hydraulic cylinder pressure by doing structural changes in boom assembly. Since boom assembly is attached to boom hydraulic cylinder, weight reduction of boom assembly is essential to reduce cylinder pressure. This weight reduction is achieved by changing plate thickness. The force on boom hydraulic cylinder get reduced by changing cylinder mounting position on boom assembly i.e. angle between boom cylinder and boom assembly. For lifting the bridge structure it is very important to evaluate the boom hydraulic cylinder force. To calculate hydraulic cylinder force, locations of center of gravity of each sub assembly should be known. The presented work in this paper mainly focuses on reduction in hydraulic cylinder pressure by doing structural analysis.

\section{STRUCTURAL ANALYSIS}

\subsection{Centre of gravity calculations of bridge structure and boom assembly}

Centre of gravity (C.G) locations and its corresponding distances from the right side of bridge is shown in Fig.1. Bridge structure splits into three different parts which are; bridge assembly, pulley assembly and pier assembly as shown in Fig.1. C.G of these individual assemblies is obtained in solid works-12 software which gives the exact location after applying material properties.

Let $M_{1}, M_{2}, M_{3}$ be the masses of three sub assemblies and $L_{1}, L_{2}, L_{3}$ be the corresponding distances of these masses from one end.

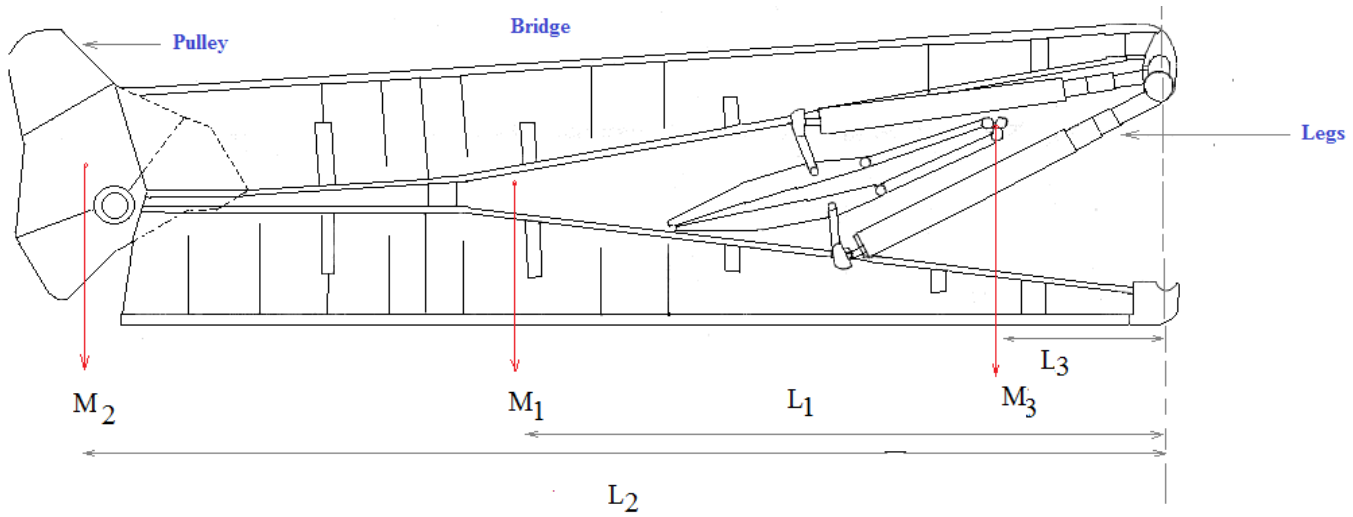

Fig.1 Schematic presentation of C.G locations of bridge sub assemblies and corresponding distances

According to principle of equivalent C.G,

C.G of Bridge $=\frac{\left(\mathrm{M}_{1} \times \mathrm{L}_{1}\right)+\left(\mathrm{M}_{2} \times \mathrm{L}_{2}\right)+\left(\mathrm{M}_{3} \times \mathrm{L}_{3}\right)}{\left(\mathrm{M}_{1}+\mathrm{M}_{2}+\mathrm{M}_{3}\right)}$

C.G of bridge $=3749 \mathrm{~mm} \quad$ (distance measure from right side)

Similarly, Lifting boom assembly is made up of high strength low alloy steel plates. There are two boom assemblies attached to launching mechanism. Two pulleys are provided on boom assembly for guiding spreading ropes and winch ropes. Boom assembly is fixed to launching mechanism at one end and free at other end. Consider two separate parts of this assembly as boom arm assembly and pulley assembly as shown in Fig.2

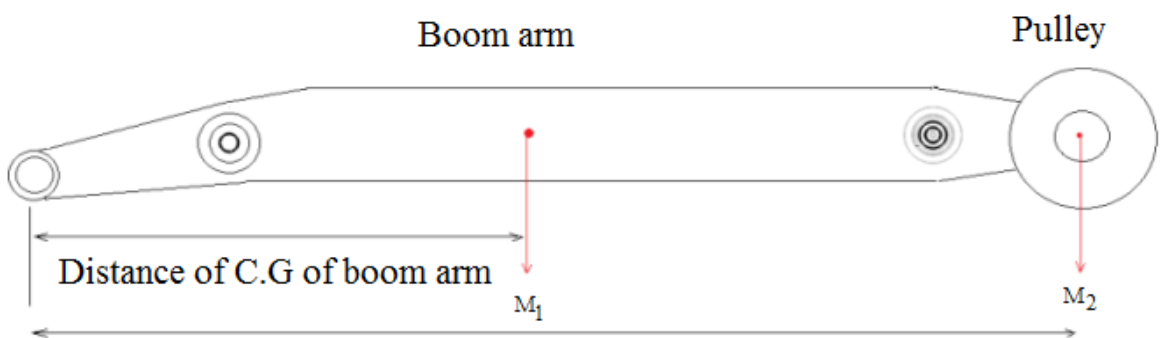

Distance of C.G of pulley

Fig.2 Representation of C.G location of boom sub assemblies from fixed end

C.G of boom assembly $=\frac{\left(\mathrm{M}_{1} \times \text { distance of C.G of arm }\right)+\left(\mathrm{M}_{2} \times \text { distance of C.G of pulley }\right)}{\left(\mathrm{M}_{1}+\mathrm{M}_{2}\right)}$

C.G of boom assembly $=1984 \mathrm{~mm}$ (distance measure from left side) 


\subsection{C.G location comparison in solid works-12 software}

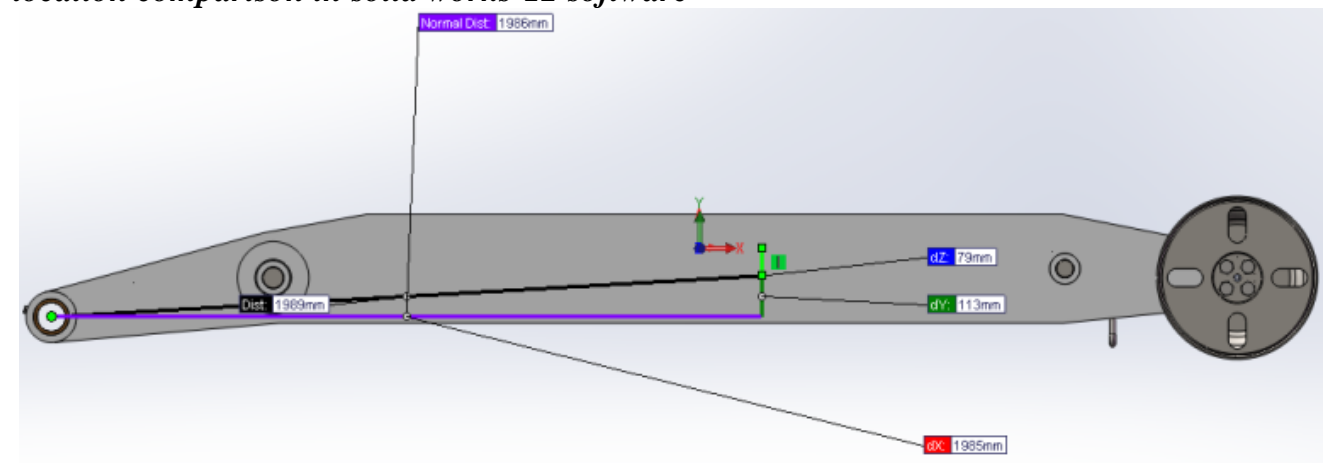

Fig.3 C.G location of boom assembly in solid works-12

Solid works-12 modeling tool has ability to calculate mass properties of any part or assembly such as volume, C.G, area, mass moment of inertia etc. after applying appropriate material to the part. By using this software, complex C.G calculations can be avoided and it is possible to find C.G of complex system easily. Fig. 3 shows the location of C.G of boom assembly from one side which is $1986 \mathrm{~mm}$.

\subsection{Structural Analysis}

Structural analysis is a mathematical examination of forces on any mechanical structure which is conducted by breaking down the structure into its component parts, then studying how each part performs and how each part contributes to the performance of the structure. The outcomes of a structural analysis are;

(1) Reactions (2) Internal member forces (3) Deflections (4) Centre of gravity (5) how much the structure bends when it is loaded. Structural analysis of individual assembly is shown in following figures. In this structural analysis, C.G of assembly, forces acted on assembly, reaction forces given by hydraulic cylinders and balancing ropes etc. are mainly focused. Structural analysis of cradle assembly is shown in Fig 4. Cradle arm assembly is $\mathrm{v}$-shaped assembly having two arms connected with tube and this assembly is mounted on vehicle rear axle. Cradle hydraulic cylinder is connected to one arm of assembly at an angle of $14^{\circ}$ with horizontal which applies about 160 bar pressure. When cradle arm starts working, it rotates about pivot point at an angle of about $55^{\circ}$. Since the structure is v-shaped and mass concentration is on both sides, C.G of total assembly lies outside at a distance of $685 \mathrm{~mm}$ from pivot point and makes an angle of $65^{\circ}$ with horizontal. 241313.5857 N.m moment is transfer about fix pivot point where cradle cylinder is attached. Boom hydraulic cylinder is mounted on cradle pivot shaft so boom cylinder applies equal and opposite reaction force on shaft.

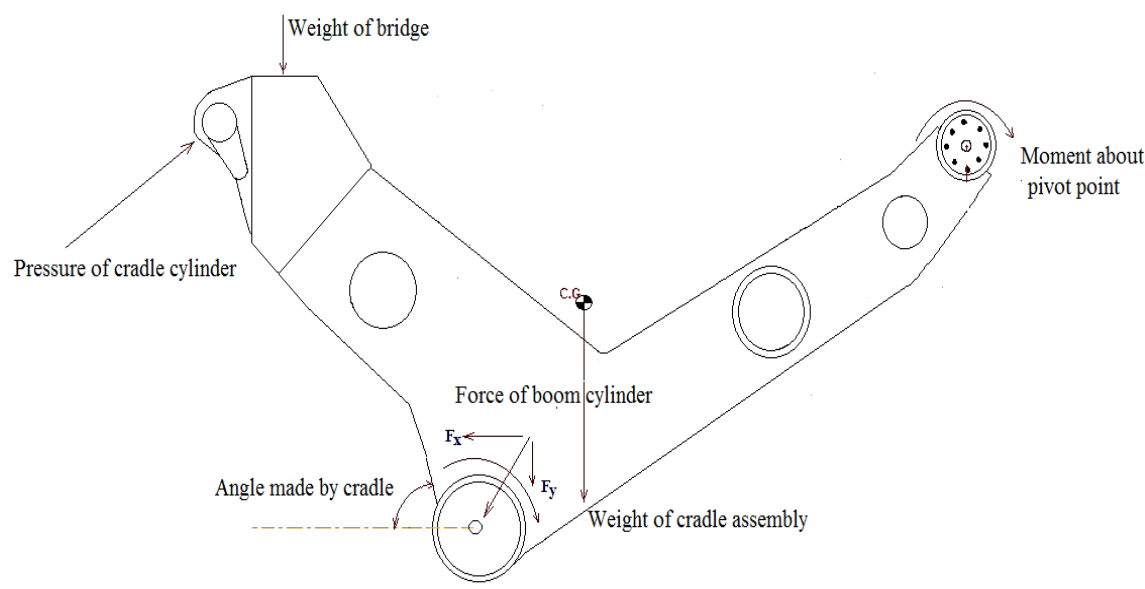

Fig.4 Structural analysis of cradle arm assembly

When the pad rests on the ground then boom cylinder starts working which applies 160 bars pressure. When boom cylinder starts working, boom is approximately at $56^{\circ}$ with horizontal so now total load of the bridge is shifted on boom. Boom takes load up to vertical position. C.G of boom lies at a distance of $1984 \mathrm{~mm}$ from boom assembly pivot point. When boom is at $90^{\circ}$, spreading rope applies tension force on pulley which is mounted on boom arm. At vertical position of boom, angle made by boom cylinder with boom arm is approximately $48^{\circ}$. As boom crosses fulcrum point, C.G of boom lies outside so that it tries to fall down but due 
to restriction of scissoring link which is used just for holding purpose, boom stops at an angle of $120^{\circ}$ with horizontal. Structural analysis of boom assembly is shown in Fig. 5

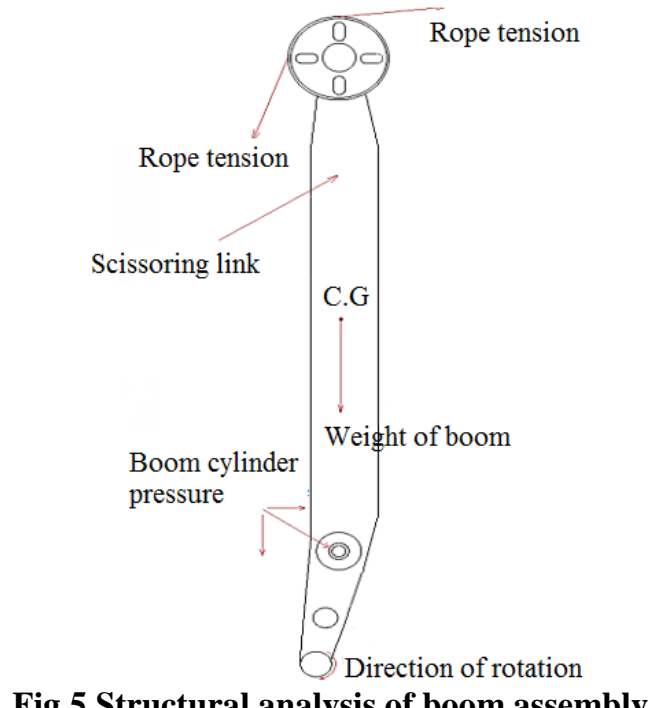

Bridge connecting assembly is directly attached to bridge deck so weight of bridge is acted on upper surface of bridge connecting assembly. Pivot point of this assembly is concentric with pivot points of boom assembly and cradle arm assembly. It rotates about pivot point along with boom assembly. C.G of connecting assembly lies at a distance $1450 \mathrm{~mm}$ from cradle pivot point when it is at horizontal position. Typical bridge connecting assembly is shown in Fig.6.

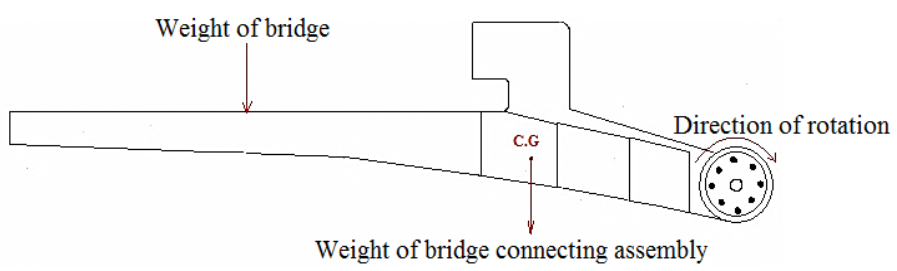

Fig.6 Structural analysis of bridge connecting assembly

\subsection{Structural analysis of total launching mechanism}

Equivalent center of gravity of total launching mechanism is calculated by using equivalent C.G principle which says that when two different bodies are at different positions, then the value of their equivalent center of mass is the sum of weights of two bodies and this C.G lies on the line joining centre of gravities of two bodies and it shifts towards the body having greater mass. At initial position of launching mechanism, center of gravity of all parts is at same position as calculated earlier by solid works software as shown in Fig.7. At second position of launching mechanism, position of center of mass of individual assemblies and position of center of mass of total launching mechanism does not change since the distances of C.G of individual assembly from fixed pivot point remains same. In vertical condition of boom i.e. at $90^{\circ}$, C.G of bridge as well as C.G of launching mechanism crosses the fulcrum point so bridge is not in balancing condition and total bridge structure is balance by spreading and winch ropes. For balancing C.G of bridge structure, area under C.G should be increase so it is necessary to scissor out the bridge immediately with the help of ropes. When the bridge scissors out fully, it makes $150^{\circ}$ angle from horizontal position. Vertical condition of launching mechanism is shown in Fig.8. 


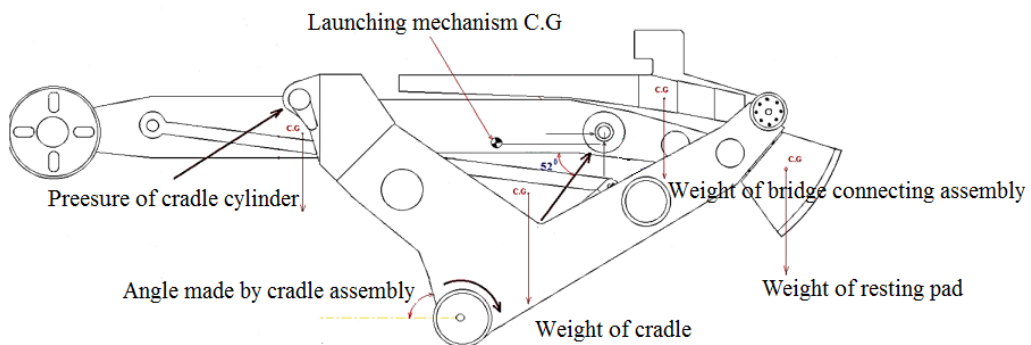

Fig.7 Initial position of launching mechanism

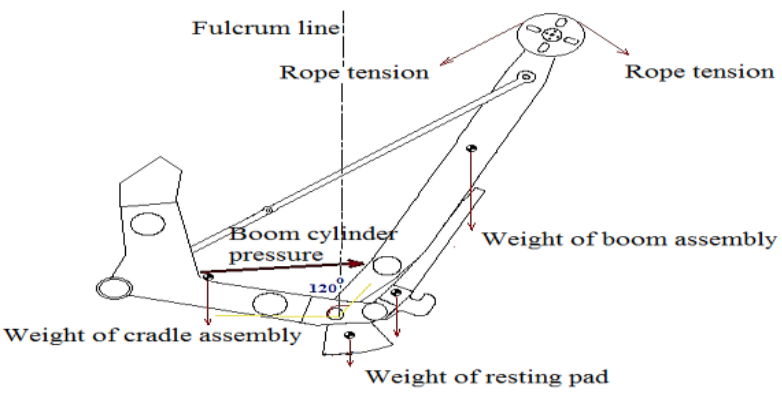

Fig.8 Final position of launching mechanism

\section{WEIGHT OPTIMIZATION}

Lifting boom assembly is made up of high strength low alloy steel plates. Weight reduction of any mechanical element can be achieved either by two ways i.e. by changing existing material or by reducing unnecessary material or both. In this case existing material selection is verified by Johnson's method of optimization. Second option is to remove unnecessary material. For reduction in weight of boom assembly, it is necessary to change plate thickness and select optimum plate thickness without changing existing material. By using ANSYS workbench, principal stresses and equivalent stresses of existed plate thickness and new optimum thickness can be compared.

Table.1 Calculated bending stress and principal stress values when only mid plate thickness changes

\begin{tabular}{|l|l|l|l|l|l|}
\hline Sr. No & $\begin{array}{l}\text { Mid plate } \\
\text { thickness }(\mathrm{mm})\end{array}$ & $\begin{array}{l}\text { Side plate } \\
\text { thickness } \\
(\mathrm{mm})\end{array}$ & $\begin{array}{l}\text { Boom } \\
\text { weight } \\
(\mathrm{kg})\end{array}$ & $\begin{array}{l}\text { Theoretical } \\
\text { Bending stress } \\
\left(\mathrm{N} / \mathrm{mm}^{2}\right)\end{array}$ & $\begin{array}{l}\text { Principal stress } \\
\left(\mathrm{N} / \mathrm{mm}^{2}\right)\end{array}$ \\
\hline 1 & 8 & 6 & 350.0 & 82.070 & 82.16 \\
\hline 2 & 7 & 6 & 337.6 & 82.074 & 82.17 \\
\hline 3 & 6 & 6 & 325.2 & 82.078 & 82.18 \\
\hline 4 & 5 & 6 & 311.4 & 82.082 & 82.19 \\
\hline 5 & 4 & 6 & 299.0 & 82.084 & 82.20 \\
\hline
\end{tabular}
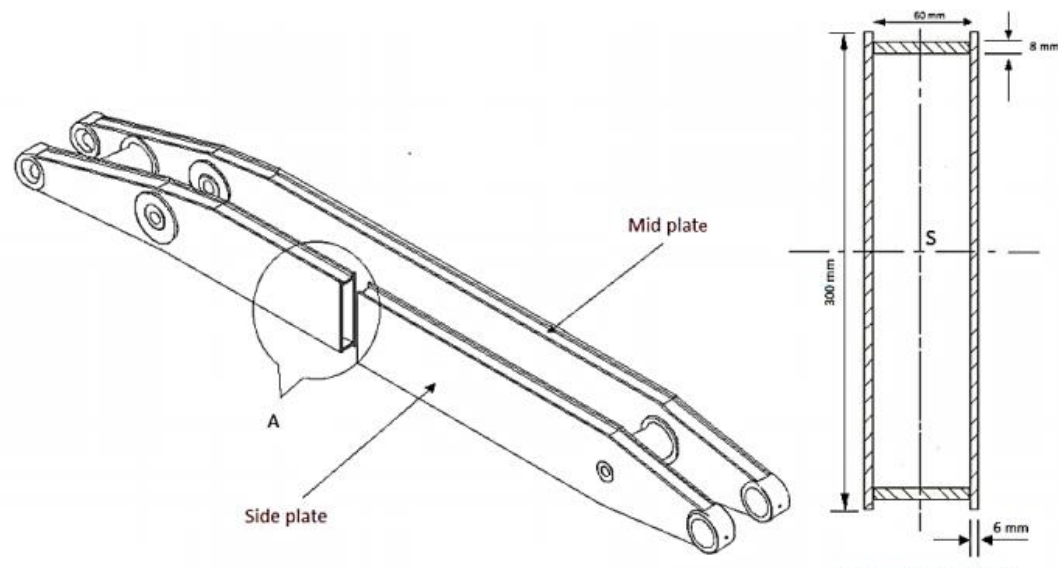

Fig.9 Boom assembly cross- sectional details

Let $t_{1}$ be the thickness of middle plate and $t_{2}$ is the thickness of side plate

At existing condition, $\mathrm{t}_{1}=8 \mathrm{~mm}, \mathrm{t}_{2}=6 \mathrm{~mm}$

Mass moment of inertia along $\mathrm{x}-\mathrm{x}$ direction

6th National Conference RDME 2017, 17th-18th March 2017.

M.E.S. College of Engineering, Pune. 411001 


$$
\begin{aligned}
& \mathrm{I}_{\mathrm{xx}}=\frac{1}{12} \mathrm{~b}_{1} \mathrm{~d}_{1}^{3}+\frac{1}{12} \mathrm{~b}_{2} \mathrm{~d}_{2}^{3}+\frac{1}{12} \mathrm{~b}_{3} \mathrm{~d}_{3}^{3}+\frac{1}{12} \mathrm{~b}_{4} \mathrm{~d}_{4}^{3} \\
& \mathrm{I}_{\mathrm{xx}}=\begin{array}{l}
27005120 \mathrm{~mm} \\
\text { Bending stress, } \sigma_{\mathrm{b}}=\frac{\mathrm{M} \times \mathrm{Y}}{\mathrm{I}} \\
\sigma_{\mathrm{b}}=82.07 \mathrm{~N} / \mathrm{mm}^{2}
\end{array} \\
& \text { Axial stress, } \sigma_{\mathrm{a}}=\frac{\text { Force in } \mathrm{x}-\text { direction }}{\text { Cross - sectional area }} \\
& \qquad \sigma_{\mathrm{a}}=1.95 \mathrm{~N} / \mathrm{mm}^{2} \\
& \text { Shear stress, } \tau=\frac{\text { Force in } \mathrm{y}-\text { direction }}{\text { Cross - sectional area }}, \tau=2.80 \mathrm{~N} / \mathrm{mm}^{2} \\
& \text { Principal stress } \sigma_{1}=82.16 \mathrm{~N} / \mathrm{mm}^{2}
\end{aligned}
$$

Similarly, the bending stresses and principal stresses are obtained for various plate thickness and tabulated in Table 1.From Table 1, it is confirm that side plate thickness $t_{1}=6 \mathrm{~mm}$ and middle plate thickness $t_{2}$ $=6 \mathrm{~mm}$ are optimum thicknesses. Plate is one type of metal sheet which have thickness greater than $6 \mathrm{~mm}$ i.e. thicknesses less than $6 \mathrm{~mm}$ are considered as sheets. From Solid works software as well as by analytical calculations, it is seen that, as plate thickness decreased by $1 \mathrm{~mm}$, weight of plate reduced by approximately 1 $\mathrm{kg}$. In this manner, weight of each plate is calculated and finally total weight of boom is evaluated. It is found that, weight of earlier lifting boom assembly was $350 \mathrm{~kg}$ which is reduced to $325 \mathrm{~kg}$ after changing plate thickness i.e. $25 \mathrm{~kg}$ weight reduction in boom assembly is achieved.

\subsection{Stress comparison by FEA}

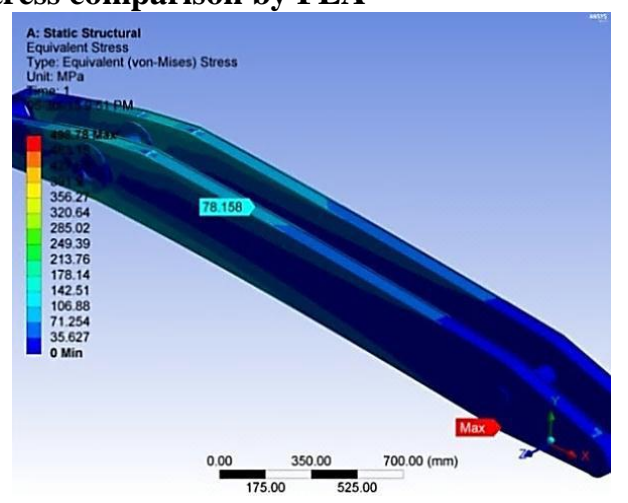

Fig.10 Equivalent stresses when $t_{1}=8 \mathrm{~mm}$ and $t_{2}=6 \mathrm{~mm}$

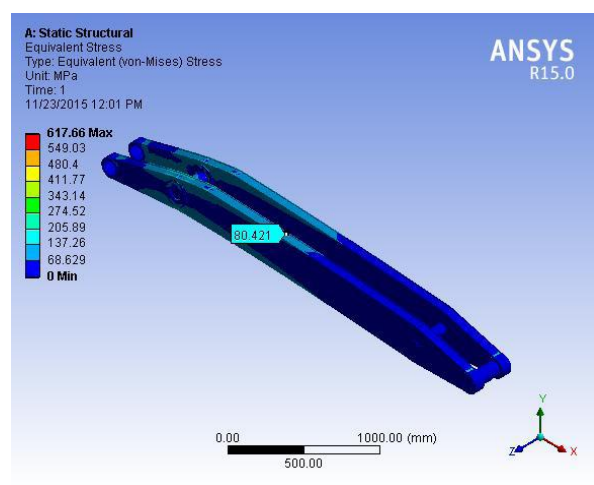

Fig.11 Equivalent stresses when $t_{1}=6 \mathrm{~mm}$ and $t_{2}=6$

Fig 10 shows the results of the stress analysis by FEA software for existing plate thickness. According to these results equivalent (von-mises) stress is $78 \mathrm{~N} / \mathrm{mm}^{2}$ at boom cross-section under consideration. Calculated equivalent stress by analytical method is $82.16 \mathrm{~N} / \mathrm{mm}^{2}$ so there is $5 \%$ difference in stress values of FEA method and analytical method. The maximum equivalent stress is $\sigma_{\max }=498.78 \mathrm{~N} / \mathrm{mm}^{2}$ which is less than yield strength of material so design is safe. Now by comparing this value with new optimum stress value in Fig. 11 it is seen that there is not much difference in these two values so new design is also safe.

\subsection{Boom cylinder force calculation}

Fig.12 shows the distances of centre of gravity of individual assemblies from fixed line on bridge deck. There are two boom assemblies as well as two bridge connecting assemblies. Force on boom cylinder can be calculated by transferring weight of all assemblies on line of action of boom cylinder. Now this arrangement is like cantilever structure in which one end is fixed as shown in Fig.13. 


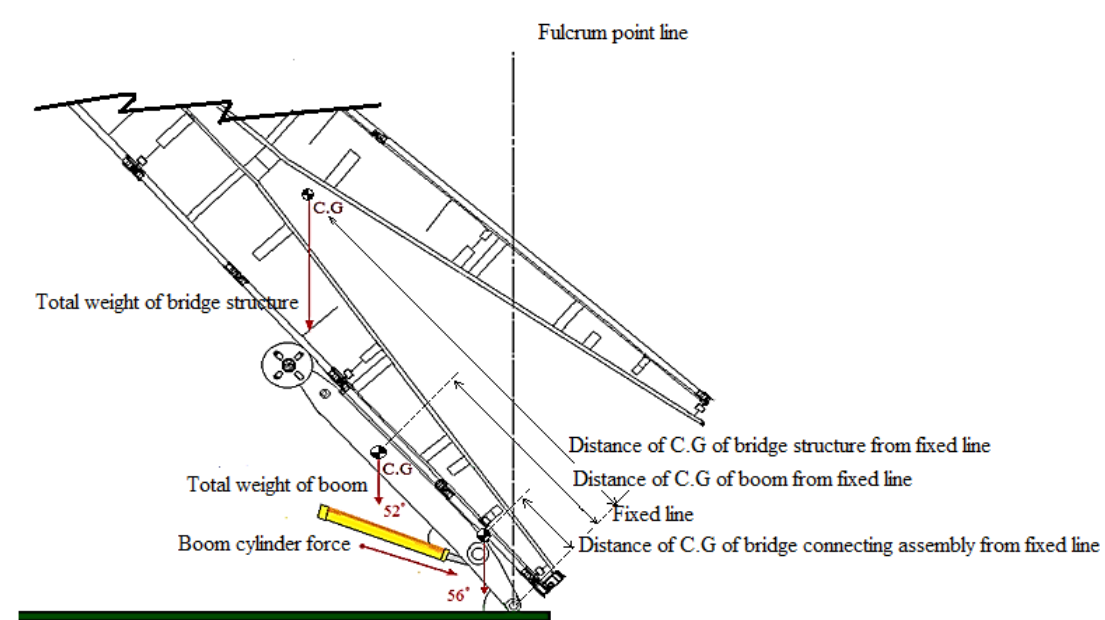

Fig.12 Lifting operation of boom cylinder

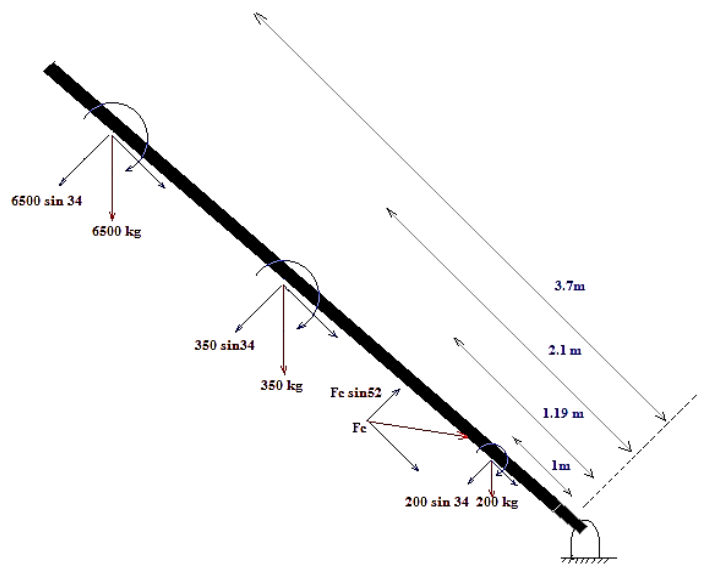

Fig.13 Schematic representation of bridge lifting position

By taking moment about fixed point, boom cylinder force can be find which is equal to $196.090 \mathrm{kN}$. From cylinder force, cylinder hydraulic pressure can be calculated as,

$$
\begin{aligned}
& \text { Pressure }=\frac{\text { Force }}{\text { Cross-secti }} \\
& \text { Pressure }(\mathrm{P})=\frac{\mathrm{F}_{\mathrm{c}}}{\frac{\pi}{4} \mathrm{~d}^{2}}
\end{aligned}
$$

Pressure $=159.7$ bar

By taking pressure readings on actual system it is found that actual boom cylinder pressure varies in between 160 to 170 bars at starting position. By comparing theoretical and practical values of boom cylinder pressure, it is concluded that pressure calculated by analytical method is in the range of pressure observed on actual system.

\subsection{Hydraulic cylinder pressure reduction}

Hydraulic cylinders get their power from pressurized hydraulic fluid, which is typically oil. Hydraulic cylinder pressure can be reduced by reducing force on cylinder. Force on cylinder can be reduced by changing the mounting position of boom hydraulic cylinder on boom assembly so that no need to change cylinder itself. Fig.14 shows existing mounting position of boom cylinder. Due to change in hydraulic cylinder mounting position, distance of cylinder mounting from pivot point increases so force automatically gets reduced to keep total moment constant as earlier position. 


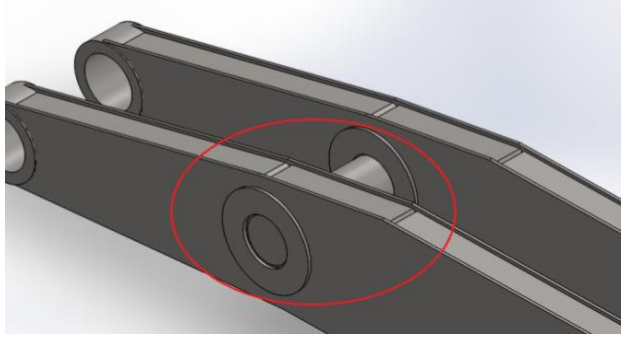

Fig.14 Existing mounting position of boom cylinder

By changing the mounting position of boom cylinder on boom assembly following parameters are changed.

1. Angle made by boom cylinder with horizontal position of boom $=1^{\circ}$

2. Angle made by boom cylinder with boom assembly $=2^{\circ}$

3. Distance between new mounting position of hydraulic cylinder and initial position $=18 \mathrm{~mm}$

Table.2 Values of pressure of boom cylinder according to angle variation

\begin{tabular}{|l|l|l|l|}
\hline Sr. No & $\begin{array}{l}\text { Angle made by boom } \\
\text { cylinder with boom }\end{array}$ & $\begin{array}{l}\text { Force on boom cylinder } \\
\text { (N) }\end{array}$ & $\begin{array}{l}\text { Pressure } \\
\text { (bar) }\end{array}$ \\
\hline 1 & $52^{\circ}$ & 196090.0526 & 159.72 \\
\hline 2 & $53^{\circ}$ & 184877.8207 & 150.60 \\
\hline 3 & $54^{\circ}$ & 174591.3370 & 142.26 \\
\hline 4 & $55^{\circ}$ & 165706.8862 & 135.03 \\
\hline 5 & $56^{\circ}$ & 165706.8862 & 127.68 \\
\hline
\end{tabular}

From Table 2 , it is found that, as the angle increased by $1^{\circ}$, pressure of boom cylinder reduced by approximately 10 bars. $\theta=56^{\circ}$ is most suitable angle which reduces boom cylinder pressure from 160 bars to 127 bars i.e. reduction in pressure is approximately 20 to $22 \%$. Angle can further be change but some geometrical parameters give the restrictions such as distance between bridge deck and pulley have to maintain around 70 to $80 \mathrm{~mm}$ but after $56^{\circ}$ this distance is not maintain so feasible value is $56^{\circ}$. Fig. 15 shows schematic diagram of launching mechanism which gives clear idea about changing position of boom hydraulic cylinder.

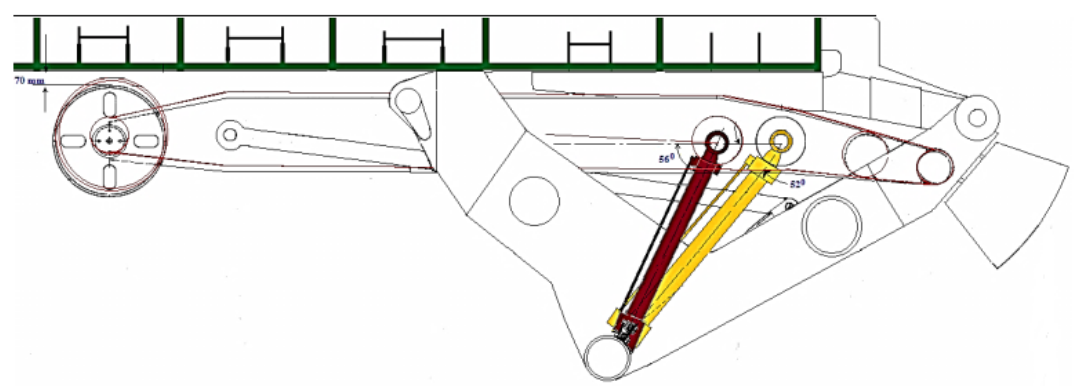

Fig.15 New proposed position of boom cylinder

Now by changing boom cylinder mounting position on boom assembly and by considering reduced weight of boom assembly simultaneously, cylinder force can be calculated which is equal to $155720.3816 \mathrm{~N}$ and hence cylinder is 126.89 bars.

\section{CONCLUSIONS}

1) Position of center of gravity of total launching mechanism remains same for first case and it varies for next case. As the C.G of bridge crosses the C.G of launching mechanism and fulcrum point, the bridge have to scissor out by ropes.

2) Von- mises stresses and principal stresses are within range for optimum plate thickness and results are verified by analytical approach hence weight of boom assembly is reduced.

3) By comparing ANSYS results for two different mounting positions, stresses produced at same sections are within range for two cases 


\section{REFERENCES}

[1] D. J. Sushir, P. N. Ulhe Failure Analysis of Centre Pin Joint Used In Heavy Assault Bridge, IOSR, Journal of Mechanical and Civil Engineering (IOSR-JMCE 7(1).

[2] B. P. Patel, J. M. Prajapati ,Evaluation of Bucket Capacity, Digging Force Calculations and Static Force Analysis of Mini Hydraulic Backhoe Excavator,machine design,4,2012, 59-66

[3] P. Shivdas et al.,Use of Six Bar Mechanism for Reduction in Force and Stroke Requirement as Against Four Bar Mechanism,US 7,568,252 B2, united states patent, Sep. 2, 2008, Attachments for transporting and launching military bridges, Aug. 4, 2009

[4] https://en.wikipedia.org/wiki/Bridge

[5] www.drdo.gov.in/drdo/pub/monographs/Introduction/military bridging.pdf

[6] https://en.wikipedia.org/wiki/DRDO_Sarvatra 